\title{
Kinetics of microbial growth with mixtures of carbon sources
}

\author{
Thomas Egli, Urs Lendenmann \& Mario Snozzi \\ Swiss Federal Institute for Environmental Science and Technology (EAWAG) and Swiss Federal Institute of \\ Technology (ETH), Überlandstrasse 133, CH-8600 Dübendorf, Switzerland
}

Key words: carbon limitation, chemostat, Escherichia coli, galactose, glucose, growth kinetics, mixed substrates, residual substrate concentration

\begin{abstract}
Several investigations have shown that during growth in carbon-limited chemostats the simultaneous utilisation of carbon substrates which usually provoke diauxie under batch conditions, i.e., 'mixed substrate growth', is probably the rule under ecologically relevant growth conditions. In contrast, the models presently available for the description of the kinetics of microbial growth are all based on the use of single substrates. Systematic studies in chemostat culture have shown that steady-state residual concentrations of individual compounds were consistently lower during mixed substrate growth than during growth with the single substrates. This effect is clearly demonstrated for the case of Escherichia coli growing with mixtures of glucose plus galactose. The data presented indicate that the extent of reduction of steady-state residual substrate concentration is dependent on the proportions of the substrates in the mixture, the nature of substrates mixed and the regulation pattern of enzymes involved in their breakdown. If this behaviour can be shown to be typical for growth under environmental conditions, it may provide an explanation why microbes still grow relatively fast at the low substrate concentrations encountered in nature.
\end{abstract}

Abbreviations: $\mathrm{S}_{0}$ - Substrate concentration in medium fed to chemostat $\left(\mathrm{mg} \mathrm{L}^{-1}\right) ; \mathrm{D}$ - Dilution rate $\left(\mathrm{h}^{-1}\right)$; DW - Biomass dry weight $\left(\mathrm{mg} \mathrm{L}^{-1}\right) ; \mu$ - Specific growth rate, $\mu_{\max }$, maximum specific growth rate $\left(\mathrm{h}^{-1}\right)$; $\mathrm{K}_{\mathrm{s}}$ - Monod affinity constant for substrate $\mathrm{s}, \mathrm{K}_{1,2}$, for substrates 1,2 , respectively $\left(\mathrm{mg} \mathrm{L}^{-1}, \mu \mathrm{g} \mathrm{L}^{-1}\right)$; $\mathrm{q}_{\mathrm{A}}$ - Specific consumption rate for substrate $A, \mathrm{q}_{\text {total }}$, total specific substrate consumption rate (mg A $\left[\mathrm{mg} \mathrm{DW}^{-1} \mathrm{~h}^{-1}\right) ; \mathrm{s}$ - Concentration of substrate in culture, $\mathrm{s}_{\mathrm{A}}$, of substrate $\mathrm{A}\left(\mathrm{mg} \mathrm{L}^{-1}, \mu \mathrm{g} \mathrm{L}^{-1}\right)$; $s_{A}$ - Steady-state concentration of substrate $\mathrm{A}$ in chemostat, $s_{A(100 \%)}$, during growth with A only, $s_{A(m i x)}$, during growth with mixture $\left(\mathrm{mg} \mathrm{L}^{-1}, \mu \mathrm{g} \mathrm{L}^{-1}\right) ; \mathrm{Y}_{\mathrm{X} / \mathrm{S}}$ - Growth yield from substrate $\mathrm{S}$ (g dry biomass $[\mathrm{g} \text { substrate }]^{-1}$ )

\section{Introduction}

For defined and reproducible laboratory studies microbiologists grow microbes in synthetic media which are usually designed such that all essential nutrients are supplied in the form of single components, e.g. glucose is supplied as a sole carbon and energy source, ammonia is the only source of nitrogen, and so on. Such nutritionally restricted conditions contrast sharply from the growth environment microorganisms encounter in ecosystems where an enormous spectrum of potential substrates are usually available to satisfy a particular physiological requirement. Especially for heterotrophic microbes a wide range of carbonaceous compounds are available, such as carbohydrates, amino acids, fatty acids, phenolic compounds etc., resulting primarily from the hydrolysis of particulate organic matter and from the excretion of metabolites by or cell lysis of primary producers (Münster \& Chróst 1990). In 


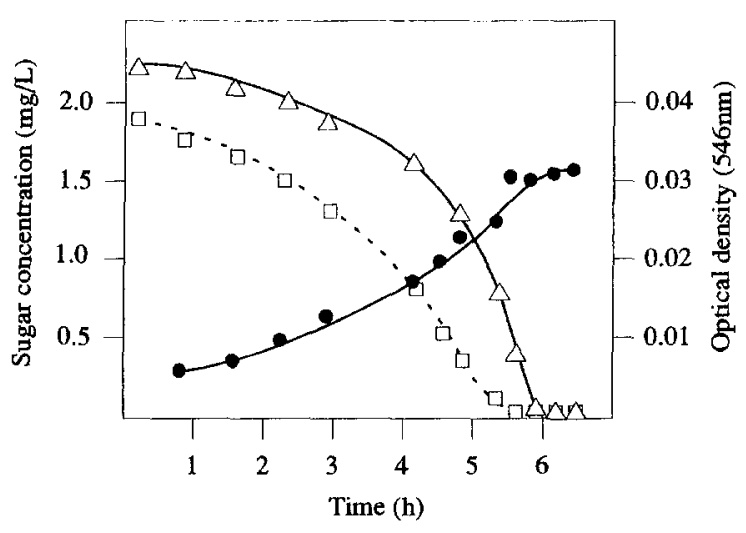

Fig. 1. Batch growth of Escherichia coli ML30 with a mixture of glucose and galactose at low initial sugar concentrations. Inoculum taken from a glucose-limited chemostat culture grown at D $=0.20 \mathrm{~h}^{-1}$ (adapted from Senn 1989). (•) Growth given as $\mathrm{OD}_{546}$; $(\square)$ glucose; $(\Delta)$ galactose.

general, environmental concentrations of low molecular weight compounds, which are considered important natural carbon substrates for heterotrophic microorganisms, are in the range of a few $\mu \mathrm{g} \mathrm{L}^{-1}$ (Münster 1993). Only transiently, such as during high photosynthetic activity of algae, concentrations of glucose or glycolic acid may increase locally to a few hundred $\mu \mathrm{g} \mathrm{L}^{-1}$ (Münster \& Chróst 1990; Münster 1993).

In contrast to the conditions prevailing in nature, the utilisation of mixtures of carbon substrates has been intensively studied under batch culture conditions at high initial concentrations ( $\mathrm{g} \mathrm{L}^{-1}$ range). When microorganisms are presented under such conditions with a mixture of homologous substrates, i.e. substrates that serve the same physiological function (Monod 1942; Harder \& Dijkhuizen 1976, 1982), they frequently exhibit a diauxic growth behaviour, where initially only the substrate which supports the highest growth rate is utilised meanwhile the consumption of poorer substrates remains repressed. The various regulatory strategies employed to achieve this goal have been studied for many different microbes but particularly detailed information at the molecular level is available for the utilisation of carbon and nitrogen sources by Escherichia coli (Postma 1986; Busby 1986; Magasanik \& Neidhardt 1987).

Although some early reports demonstrated that the simultaneous utilisation of two 'diauxic' carbon substrates can occur at high concentrations in batch cultures (Monod 1942) as well as in carbon-limited (Mateles et al. 1967; Baidya et al. 1967; Harte \& Webb 1967; Silver \& Mateles 1969) or nitrogen-limited chemostat cultures (NG \& Dawes 1973) little attention has been paid to this phenomenon. Nevertheless, a number of investigations have demonstrated that the simultaneous utilisation of carbon substrates, i.e. 'mixed substrate growth', is a frequently observed phenomenon (reviewed in Harder \& Dijkhuizen 1976, 1982; Wanner \& Egli 1990; Egli \& Mason 1991). The information presently available supports the conclusion that in batch culture simultaneous utilisation of 'diauxic' carbon substrates occurs when initial substrate concentrations are low (Fig. 1). In batch culture it has also been observed at high initial substrate concentrations with combinations of carbon substrates supporting only medium to low maximum specific growth rates; occasionally, this leads to a synergistic effect resulting in increased specific growth rates compared to growth with the single substrates (Babel 1982). For carbon-limited chemostat cultures there is now strong evidence that the utilisation of mixtures of 'diauxic' carbon substrates at low and medium dilution rates (relative to $\mu_{\max }$ ) is the rule rather than the exception and an example is shown in Fig. 2.

All this information suggests that under natural

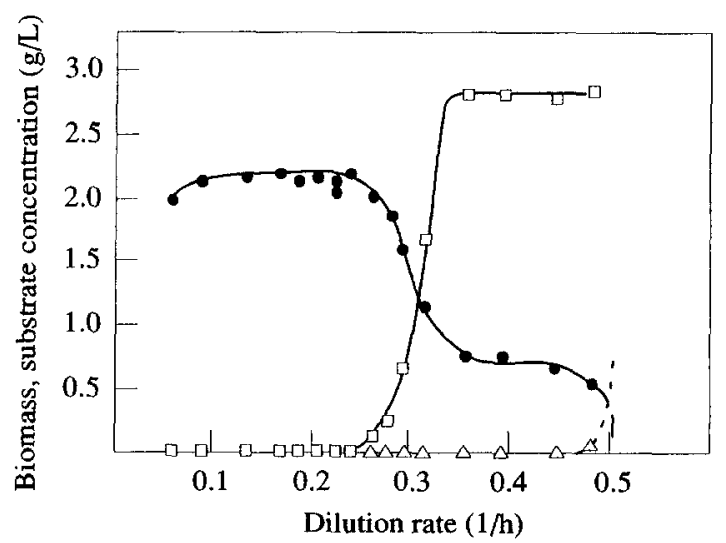

Fig. 2. Growth of the methylotrophic yeast Hansenula polymorpha in chemostat culture with a mixture of glucose and methanol. Concentrations of glucose and methanol in the inflowing medium were $1.94 \mathrm{~g} \mathrm{l}^{-1}$ and $3.06 \mathrm{~g} \mathrm{l}^{-1}$, respectively. $(\bullet)$ Dry biomass; $(\triangle)$ glucose; $(\square)$ methanol (from Egli et al. 1982). 
conditions a heterotrophic microbe is unlikely to rely on a single carbon compound for growth but that it will make use of as many as possible of the different substrates available in its environment. Despite this fact, kinetic equations used today to describe microbial growth in nature are still based on the assumption that the extracellular concentration of a single substrate (s) is governing the growth rate $(\mu)$. Many different equations have been proposed to describe the relationship between $s$ and $\mu$ (reviewed in Jannasch \& Egli 1993). Though, that originally proposed by Monod (1942)

$$
\mu=\mu_{\max } \frac{\mathrm{s}}{\left(\mathrm{K}_{\mathrm{s}}+\mathrm{s}\right)}
$$

is still the one which is most widely used to describe microbial growth, competition and biodegradation kinetics under environmental conditions (Bazin 1982; Simkins \& Alexander 1984; Gottschal 1993).

Some efforts have been made to develop kinetic models that describe simultaneous growth with substrate mixtures in the same way that models have been established for single substrates (MeGee et al. 1972; Blanch \& Yoon 1977; Bader 1982; Kompala et al. 1984; Lee et al. 1984; Baltzis \& Fredrickson 1988; Mankad \& Bungay 1988), both for homologous (e.g. carbon substrates) and heterologous (e.g. a carbon plus a nitrogen source) nutrients. Generally it was assumed that a combination of two or more (modified) Monod terms (eq.1) would adequately describe growth under these conditions, as initially proposed by MeGee et al. (1972):

$$
\mu=\mu_{\max } \frac{\mathrm{s}_{1}}{\left(\mathrm{~K}_{1}+\mathrm{s}_{1}\right)} \frac{\mathrm{s}_{2}}{\left(\mathrm{~K}_{2}+\mathrm{s}_{2}\right)}
$$

However, due to the lack of experimental data such models rely exclusively on mathematical reasoning.

\section{Kinetics of mixed carbon substrate growth: experimental data}

Most investigations on mixed substrate growth of microbes have concentrated on macroscopic (substrate utilisation and biomass formation), biochemical (enzyme regulation) or competitive aspects (Harder \& Dijkhuizen 1982; Egli \& Mason 1990;
Gottschal 1993) and only rarely have experimental data been published on growth-limiting concentrations of individual substrates under such conditions.

The first experimental kinetic data were reported by Law \& Button (1977) for a marine Corynebacterium $\mathrm{sp}$. with measurement of the residual steadystate concentrations of glucose, $s_{\text {glucose }}$, during carbon-limited growth with various mixtures of glucose and amino acids in chemostat culture. They found that addition of arginine, arginine plus glutamate, or a mixture of twenty amino acids always resulted in a lowered $s_{\text {glucose }}$. For growth at a constant $\mathrm{D}$ of $0.03 \mathrm{~h}^{-1}$, the effect was most pronounced for the amino acid mixture where $s_{\text {glucose }}$ dropped from 210 $\mu \mathrm{g} \mathrm{L}^{-1}$ with glucose supplied as the only substrate in the feed $\left(S_{0}=2.5 \mathrm{mg} \mathrm{L}^{-1}\right)$ to less than $10 \mu \mathrm{g} \mathrm{L}^{-1}$ when the mixture fed consisted of mixed amino acids (1 $\left.\mathrm{mg} \mathrm{L}^{-1}\right)$ together with glucose $\left(1.7 \mathrm{mg} \mathrm{L}^{-1}\right)$. A similar observation was made for the growth of a methylotrophic yeast in chemostat culture at a constant dilution rate with different mixtures of glucose and methanol (Egli et al. 1983). Also in this case, the resulting $s_{\text {methano }}$ was always lower during growth with substrate mixtures as compared to growth with methanol alone. The concentration of methanol exhibited a characteristic dependence on the ratio of glucose/methanol supplied in the feed as shown in Fig. 7.

The two sets of data indicate that the extent of the effect might be dependent on the composition and the nature of the substrate mixture supplied for growth. It is of course tempting to speculate that the reduction of steady-state concentrations of individual carbon substrates during growth with substrate mixtures - as compared to the concentrations measured for growth with single carbon sources - might be a general kinetic principle valid for the growth of virtually any heterotrophic microorganism, even with more complex substrate mixtures. Unfortunately, in both studies the concentration of only one substrate component was followed analytically and the effect on the steady-state concentration of the second nutrient component remains unknown.

From all this it is obvious that for a better understanding of mixed substrate growth kinetics more experimental data is needed concerning residual concentrations of two or more individual growth- 


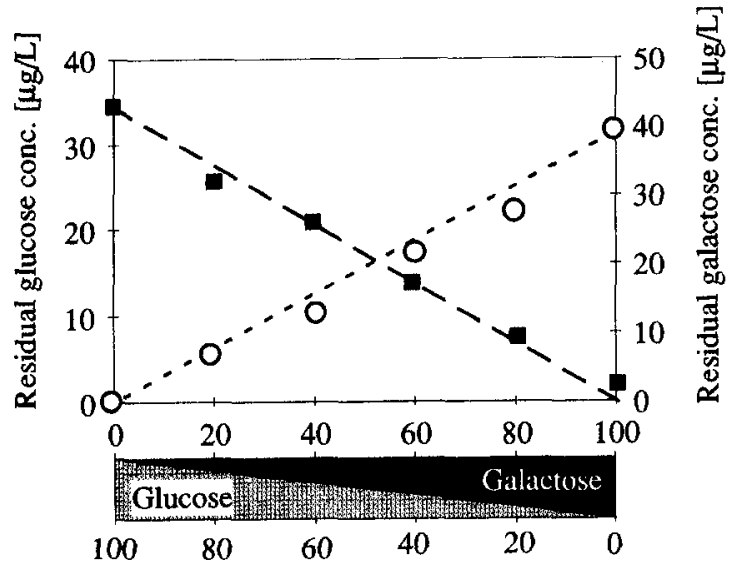

Proportions of sugars in inflowing medium [\%,w/w]

Fig. 3. Steady-state concentrations of glucose ( $\boldsymbol{(})$ and galactose $(O)$ in a chemostat culture of Escherichia coli growing carbonlimited at a constant dilution rate $\left(\mathrm{D}=0.30 \mathrm{~h}^{-1}\right)$ with different glucose:galactose mixtures in the feed. The total sugar concentration in the inflowing medium was always $10 \mathrm{mg} \mathrm{L}^{-1}$ and the mixture composition of glucose:galactose is given in $\%(w / w)$. Data from Lendenmann et al. (1992).

limiting substrates during mixed substrate growth of microbial cultures in chemostats, under both steady- and transient-state conditions. Such information is of fundamental importance, not only to improve our basic concepts in microbial ecology, but also for a better understanding of, for example, the kinetics of pollutant degradation by microorganisms in the environment where such compounds compete with the naturally available substrates.

\section{Growth of Escherichia Coli with mixtures of sugars}

Until now the availability of this data has been restrained by analytical limitations. In response to this a method was developed in our laboratory which permits rapid and reproducible determination of reducing sugars in culture media in the $\mu \mathrm{g} \mathrm{L}^{-1}$ concentration range (Senn 1989; Senn et al. 1993). Applying this analytical method, the growth of $E$. coli in a carbon-limited chemostat at a constant dilution rate $\left(D=0.3 \mathrm{~h}^{-1}\right)$ with defined mixtures of glucose and galactose has been investigated as a model system (Lendenmann et al. 1992) and the data obtained for the steady-state concentrations of the two sugars are shown in Fig. 3. As expected at the low dilution rate imposed $\left(\mu_{\max }\right.$ with either glucose or galactose was approximately $0.90-0.92 \mathrm{~h}^{-1}$ ), both sugars were utilised simultaneously independent of the ratio of the two sugars supplied in the feed. The data clearly demonstrate that the residual steady-state concentrations of both glucose and galactose were always lower during growth with mixtures than during growth with the single substrates. These results were confirmed for various total sugar concentrations in the feed $\left(S_{0}=1,10\right.$ and $100 \mathrm{mg}$ $\mathrm{L}^{-1}$ ) and they were always the same, irrespective of whether the experiments were initiated with glucose only after which a mixture with galactose was fed, or vice versa. In addition, as tested for a mixture of glucose:galactose (1:1), the phenomenon was not dependent of the growth rate between $\mathrm{D}=0.3$ and $0.7 \mathrm{~h}^{-1}$ (Lendenmann et al. 1992).

The fact that the growth yield for the two sugars was identical $\left(\mathrm{Y}_{\mathrm{X} / \mathrm{S}}=0.45\right)$ and additive during growth with glucose/galactose mixtures implies that the pattern observed for the steady-state concentrations of the two sugars closely reflects that for the individual specific sugar consumption rates, $q_{\text {glucose }}$ and $\mathrm{q}_{\text {galactose }}$, respectively. As indicated in eq. 3 and 4 , both of these become a function of the composition of the substrate mixture in the medium when the

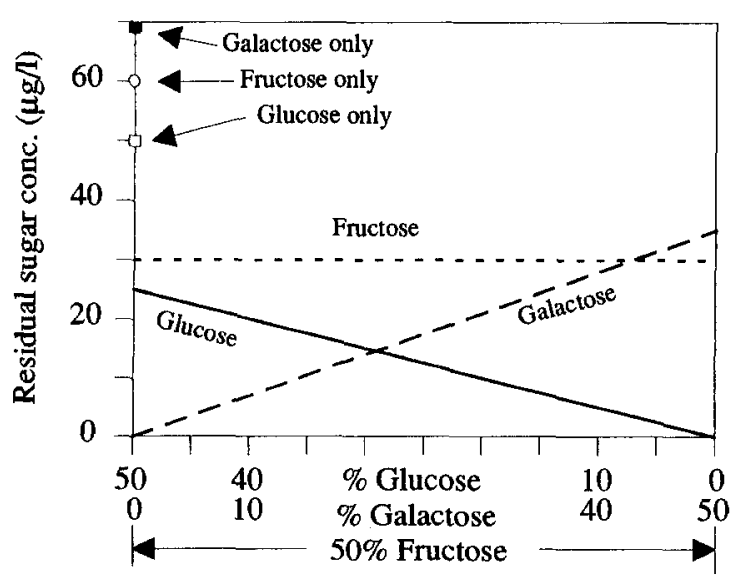

Mixture composition in feed

Fig. 4. Predicted steady-state concentrations of glucose, galactose and fructose in a chemostat culture of Escherichia coli growing carbon-limited at a constant dilution rate with different mixtures of glucose:galactose:fructose. The relative proportion of fructose is kept constant. Theoretical residual concentrations of individual sugars for single-substrate-limited growth are indicated. 


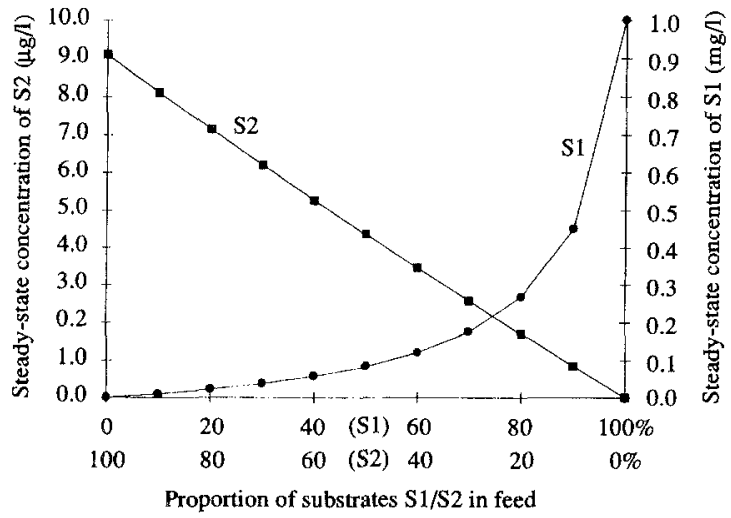

Fig. 5. Predicted steady-state substrate concentrations during simultaneous utilisation of two growth-limiting substrates S1 (•) and S2 (-) at a constant dilution rate in a chemostat, as a function of the proportion of the two substrates in the feed (given in \% w/w). At high proportions of S1 in the feed the pathway for S1 is operating close to saturation, whereas for all substrate mixtures the pathway for S2 is working far from saturation. Parameters used for calculation: $\mathrm{K}_{\mathrm{s}}$ for both substrates $0.1 \mathrm{mg} \mathrm{L}^{-1} ; \mathrm{q}_{\mathrm{s} 1}$ and $\mathrm{q}_{\mathrm{s} 2}$ varying from $0-1.0 ; \mathrm{q}_{\max (\mathrm{S} 1)}=1.1 \mathrm{~h}^{-1} ; \mathrm{q}_{\max (\mathrm{S} 2)}=12 \mathrm{~h}^{-1}$.

sugars are utilised simultaneously (Lendenmann 1992; compare also Fig. 3):

$$
\begin{aligned}
& \mathrm{q}_{\text {glucose }} \approx D \frac{\mathrm{S}_{0 \text { (glucose })}}{\left(\mathrm{S}_{0 \text { (glucose })}+\mathrm{S}_{0(\text { galactose })}\right) \mathrm{Y}_{\mathrm{X} / \mathrm{S}}} \\
& \mathrm{q}_{\text {galactose }} \approx \mathrm{D} \frac{\mathrm{S}_{0(\text { galactose })}}{\left(\mathrm{S}_{0 \text { (glucose })}+\mathrm{S}_{0(\text { galactose })}\right) \mathrm{Y}_{\mathrm{X} / \mathrm{S}}}
\end{aligned}
$$

Hence, a first simple model can be put forward for growth of $E$. coli with glucose/galactose mixtures in which, for a fixed dilution rate, the steady-state concentration of glucose $s_{\text {glucose(mix) }}$ can be described as a function of the flux of a sugar into the cell, i.e. the specific sugar consumption rate (eq. 5), or the mixture composition supplied in the medium reservoir (eq. 6):

$$
\begin{aligned}
& s_{\text {glucose }(\text { mix })}=s_{\text {glucose }(100 \%)} \frac{\mathrm{q}_{\text {glucose }}}{\left(\mathrm{q}_{\text {glucose }}+\mathrm{q}_{\text {galactose }}\right)} \\
& s_{\text {glucose }(\text { mix })}=s_{\text {glucose }(100 \%)} \frac{\mathrm{s}_{0(\text { glucose })}}{\left(\mathrm{s}_{0 \text { (glucose })}+\mathrm{s}_{\text {0(galactose })}\right)}
\end{aligned}
$$

and vice versa for galactose.

Supposing that this simple model is also valid for more complex sugar mixtures (assuming constant growth rate and identical and constant growth yield for all sugars) it implies that the steady-state con- centrations of an individual sugar $\mathrm{A}, s_{A(m i x)}$, would be linearly related to its proportion, $\mathrm{q}_{\mathrm{A}}$, contributing to the total substrate flux, $\mathrm{q}_{\text {total }}$ into the cell:

$$
\begin{aligned}
& s_{A(\text { mix })}=s_{A(100 \%)} \mathrm{q}_{\mathrm{A}} /\left(\mathrm{q}_{\text {total }}\right) \\
& s_{A(m i x)}=s_{A(100 \%)} \mathrm{S}_{0(\mathrm{~A})} /\left(\mathrm{S}_{0(\text { total })}\right)
\end{aligned}
$$

This implies that in the above described experimental system the residual steady-state concentration of a sugar contributing always the same proportion of carbon to the total substrate flux would stay constant, irrespective of the relative proportion of all the other substrate components, as shown in Fig. 4. This has been confirmed for $E$. coli growing with a mixture of glucose, galactose and fructose where the proportion of fructose in the mixture was kept constant, whereas the relative contribution of glucose and galactose was altered (Lendenmann et al. 1992).

\section{Effect of enzyme concentration on steady-state substrate concentrations}

It has been frequently pointed out that the steadystate residual substrate concentrations observed in a chemostat culture and the content of transport proteins and catabolic enzymes of cells influence each other (reviewed in Button 1985; Rutgers et al. 1991). When we discuss such interactions for the

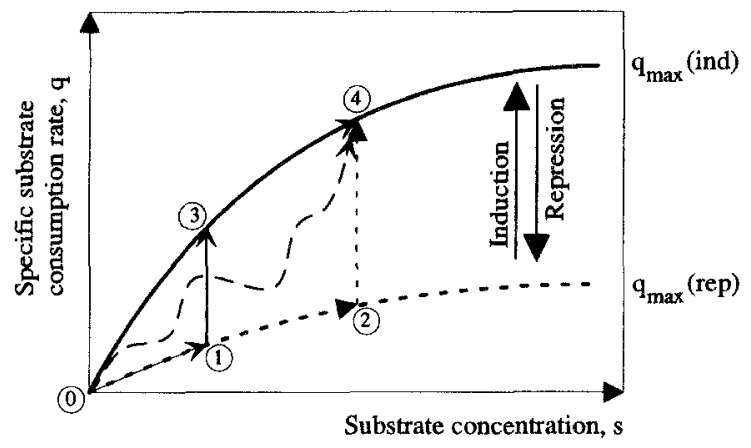

Fig. 6. Effect of enzyme regulation on the relationship between specific substrate consumption rate and steady-state substrate concentration. It is assumed that the consumption kinetics of a microbial culture for a substrate, $q_{s}$ as $f(s)$, can be described by a Monod-type relationship. $\mathrm{q}_{\max }$ (ind) and $\mathrm{q}_{\max }$ (rep) are the maximum specific substrate consumption rates under fully induced (repressed) conditions. Definition of numbers is discussed in the text. 


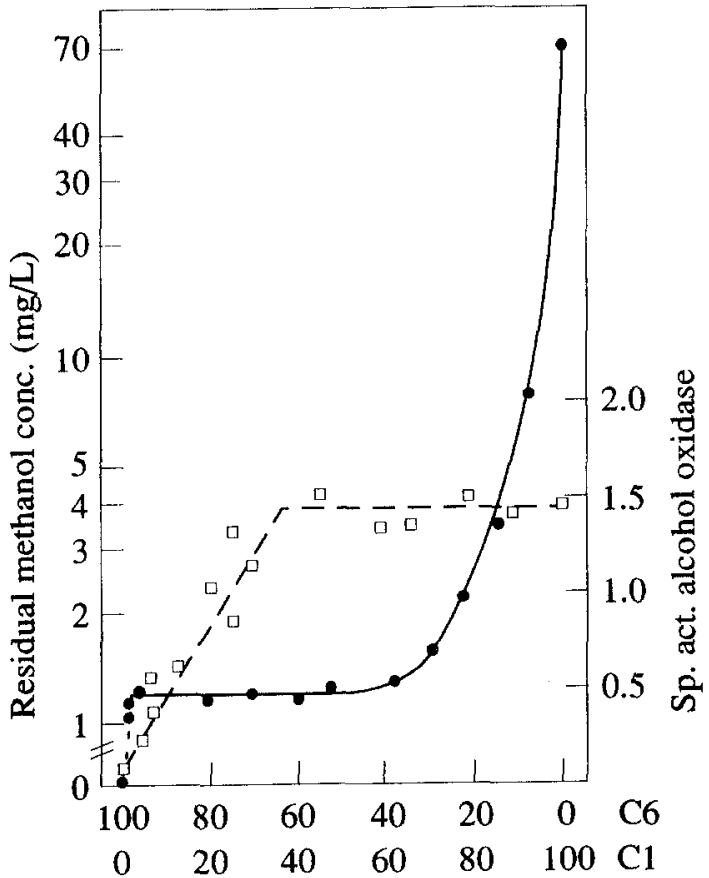

Proportions of glucose (C6) and methanol (C1) in inflowing medium $(\%, w / w)$

Fig. 7. Steady-state methanol concentration $(\bullet)$ and specific activity of alcohol oxidase ( $\square$ ) in the yeast Kloeckera sp. 2201 during simultaneous utilisation of glucose/methanol mixtures in carbon-limited chemostat culture at constant dilution rate. The enzyme pattern of alcohol oxidase is representative for all enzymes involved in the dissimilation and assimilation of methanol. Specific activity of alcohol oxidase is given in $\mu \mathrm{mol}(\mathrm{mg}$ protein min) $)^{-1}$. Adapted from Egli et al. 1982, 1983.

growth of E. coli with mixtures of glucose and galactose described above, two altogether different regulation strategies for the enzymes involved in the catabolism of the two sugars can be proposed:

1. the rate of synthesis of the different enzymes is not affected by changes in the glucose/galactose mixture composition, or

2. the cellular concentration of the different enzymes is subject to regulation and is in some manner dependent on the individual fluxes of the two carbon substrates.

For simplicity, it can be assumed that the substrate consumption kinetics of the culture for individual substrates, i.e., $\mathrm{q}_{\mathrm{s}}$ as $\mathrm{f}(\mathrm{s})$, can be described by a Monod-type relationship under all conditions.

Considering first the case where the cellular enzyme composition remains constant, two different patterns can be anticipated for the residual concentration of a substrate in response to changes in the supplied substrate mixture, depending on whether the pathway will have to operate in the saturated or the non-saturated region. Under the former conditions a distinctly non-linear relationship between external substrate concentration and $q_{s}$ should be observed. In the latter case one would expect an almost linear relationship between flux $\left(\mathrm{q}_{\mathrm{s}}\right)$ and steady-state concentration of the corresponding substrate. The patterns expected are shown in Fig. 5 for two different substrates S1 and S2. Hence, the residual substrate patterns observed for $E$. coli growing on different glucose/galactose mixtures at $\mathrm{D}=0.30$ $\mathrm{h}^{-1}$ suggests that the enzyme content of the cells with respect to glucose and galactose metabolism was not subjected to extensive regulation but remained more or less constant and that the two pathways were operating at the sub-saturated level.

The different options to relate $\mathrm{q}_{\mathrm{s}}$ and residual substrate concentration for the case where the enzymes of a pathway are subjected to regulation in response to changes in the metabolic flux are schematically outlined in Fig. 6. Considering a culture growing under non-induced conditions with a substrate $\mathrm{A}$ and assuming that the cells still contain a derepression level of catabolic enzymes for a second substrate $B$, as indicated by curve $q_{\max }$ (rep), small proportions of $\mathrm{B}$ added to the feed can be handled without the need to increase the capacity of

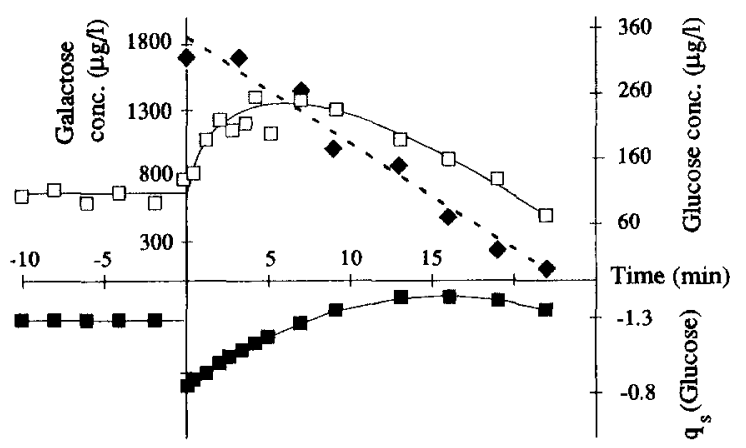

Fig. 8. Concentration of glucose $(\square)$, galactose $(\bullet)$ and specific glucose consumption rate ( $\square$ ) before and after a pulse of galactose into a steady-state culture of Escherichia coli growing in a glucose-limited chemostat at a constant dilution rate of $0.67 \mathrm{~h}^{-1}$. $\mathrm{q}_{\mathrm{s}}$ (glucose) is given in g glucose $(\mathrm{g} \text { dry biomass } \mathrm{h})^{-1} ; \mathrm{S}_{0}$ (glucose $)=$ $10 \mathrm{mg} \mathrm{L}^{-1}$ (Weilenmann HU, Lendenmann U \& Egli T, unpubl. results). 
the pathway. Hence, up to point (2) $-s_{B}$ will rise as $q_{B}$ is increased. At (2) a further increase in substrate flux cannot be achieved simply by an enhanced external substrate concentration and it becomes necessary to increase the capacity of the pathway, i.e., induction is triggered. Now an increase in substrate flux $q_{B}$ is achieved by enhancing the amount of enzyme in the pathway until full induction is reached, whereas the external concentration of $\mathrm{B}$ can, in principle, remain constant (path (0) $\rightarrow$ (1) $\rightarrow$ (2) $\rightarrow$ (4)). Alternatively, induction could be triggered already by low substrate fluxes resulting in an initially constant substrate concentration until the pathway is fully induced; a subsequent increase in $\mathrm{q}_{\mathrm{s}}$ is then coupled to enhanced concentrations of the substrate (indicated by path (0) $\rightarrow$ (1) $\rightarrow$ (3) $\rightarrow$ (4)). These simplified $\mathrm{q}_{\mathrm{s}}$ vs. $s$ patterns can of course be less clear cut as indicated by the direct path (0) $\rightarrow$ (4) in Fig. 6.

Experimental verification of the above hypothesis can be demonstrated by the results obtained for the methylotrophic yeast Klöckera sp. 2201 during the simultaneous utilisation of glucose and methanol in a carbon-limited chemostat at a constant dilution rate (Fig. 7). For this yeast the specific activities of enzymes involved in the dissimilation and the assimilation pathway of methanol together with the residual methanol concentration have been measured (Egli et al. 1982, 1983). During growth with low proportions of methanol $(<50 \%, w / w)$ the cells used the strategy of regulating the amount of enzyme in the pathway in order to sustain the increasing carbon flux. This resulted in an essentially constant external methanol concentration of $1.2 \mathrm{mg} \mathrm{L}^{-1}$. However, when the flux of carbon through the methanol pathway exceeded $50 \%$ all enzymes of the pathway were fully induced, and, in order to support the increase in the specific methanol consumption rate necessary to maintain the growth rate, the external methanol concentration increased to approximately $70 \mathrm{mg} \mathrm{L}^{-1}$. This experimental evidence indicates that residual substrate patterns are intimately linked to enzyme concentration in a metabolic pathway and that knowledge of the regulatory enzyme pattern is necessary to predict residual substrate concentrations.

\section{Substrate consumption kinetics under transient-state conditions}

In all the examples and considerations above it was assumed that steady-state growth conditions were established. However, in ecosystems growth rarely takes place under such ideal conditions and the availability of nutrients, including the carbon sources, frequently oscillates (Münster 1993). It is therefore of considerable interest to know more about microbial substrate consumption and growth kinetics under transient-state conditions. An example for the interaction of two sugars, glucose and galactose, is shown in Fig. 8 where galactose was pulsed into a steady-state culture of $E$. coli growing at $\mathrm{D}=$ $0.67 \mathrm{~h}^{-1}$ (approx. $75 \%$ of $\mu_{\max }$ ) with glucose as the only carbon source in a chemostat. The cells were able to instantaneously utilise galactose simultaneously with glucose at a rate of approximately $-1 \mathrm{~g}$ galactose $(\mathrm{g} \mathrm{DW} \mathrm{h})^{-1}$. This corresponds to $80 \%$ of the specific rate of glucose consumed during steady-state growth before the pulse. The data also demonstrate that, even at the low concentration of $1.8 \mathrm{mg} \mathrm{L}^{-1}$, galactose was able to immediately reduce the rate of glucose consumption from -1.3 to $0.8 \mathrm{~g}$ glucose $(\mathrm{g} \mathrm{DW} \mathrm{h})^{-1}$. The reduction of the rate of glucose consumption by galactose resulted in a transient increase in the residual concentration of glucose from 0.6 up to $1.3 \mathrm{mg} \mathrm{L}^{-1}$ in the chemostat. However, as the concentration of galactose decreased the rate of glucose consumption recovered and for a short period became even higher than before the pulse. It remains to be established at what level glucose utilisation is inhibited by galactose. This experiment suggests that carbon-starved heterotrophs exhibit a considerable flexibility with respect to carbon utilisation and that many of them might be able to quickly replace a primary substrate by another substrate which is transiently more abundant in the environment.

\section{Some conclusions and outlook}

From the information presented above it seems reasonable to deduce two general principles for the growth of heterotrophic microbes: First, under car- 
bon-limited conditions heterotrophic microbes exhibit a strong potential for mixed substrate growth and they will utilise many different carbon substrates simultaneously. There are indications that the spectrum of carbon sources utilised might become wider as the degree of starvation increases at decreasing growth rates (Matin 1979), but this property of heterotrophs has not yet been studied systematically. Secondly, in all examples investigated so far, residual steady-state concentrations of individual carbon substrates were reduced during growth with mixtures in comparison to growth with single substrates. Both abilities will enable a heterotrophic microorganism to grow relatively fast at the low concentrations of individual carbon substrates confronted within ecosystems. The consequences with respect to competition are discussed in this issue by Gottschal (1993).

The observation that microbes are able to utilise carbon substrates down to very low concentrations if the substrates contribute to only a low fraction of the total carbon utilised raises many interesting questions with respect to substrate threshold concentrations during mixed substrate growth. Law \& Button (1977) observed for a marine Corynebacterium that the threshold concentration for glucose utilisation was significantly lower during growth with a $1: 1$ mixture of glucose plus arginine $(80 \mu \mathrm{g}$ $\left.\mathrm{L}^{-1}\right)$ compared to growth with glucose only $(210 \mu \mathrm{g}$ $\left.\mathrm{L}^{-1}\right)$. But this was not a threshold for utilisation in an absolute sense because when $1 \mu \mathrm{g} \mathrm{L}^{-1}$ of glucose was fed together with $1.25 \mathrm{mg} \mathrm{L}^{-1}$ of a mixture of amino acids most of the glucose was still utilised down to a steady-state concentration of $0.3 \mu \mathrm{g} \mathrm{L}^{-1}$. In our experiments with $E$. coli we detected no apparent limiting concentration for both glucose and galactose below which the cells were not able to further reduce the residual concentration of these sugars and one must conclude that an existing threshold concentration must be below the detection limit of $2 \mu \mathrm{g}$ $\mathrm{L}^{-1}$. This strongly suggests that threshold concentrations obtained for growth with single substrates cannot be related to the actual substrate utilisation potential of cells growing under environmental conditions in the presence of complex substrate mixtures, but the lack of good data on this aspect is all too obvious. The question of residual and thresh- old concentrations is particularly relevant when the degradation of pollutants in the presence of easily degradable natural carbon substrates is considered.

Despite the fact that simple models ignoring enzymatic cell composition could be used to describe mixed substrate growth of $E$. coli with glucose and galactose, some experimental data demonstrate that kinetic performance of cells is definitely influenced by the synthesis pattern for relevant enzymes. In addition to such short term mechanisms, long term adaptation (discussed in Jannasch \& Egli 1993) and 'memory effects' (Lengeler 1993) must be considered. They may lead to hysteresis kinetics.

A future task will certainly be to develop structured kinetic models which quantitatively connect external substrate concentrations with cellular enzyme content and activity. First steps in this direction have been discussed in the contributions of Button (1993) and Van Dam et al. (1993). Furthermore, we would like to recall that, in addition to the kinetics of mixed carbon substrates discussed here, there is very little known about kinetic interactions between heterologous substrates during multiplenutrient-limited growth conditions (see Rutgers et al. 1990; Egli 1991). We are presently only seeing the tip of an iceberg which awaits exploration!

\section{Acknowledgements}

The authors are indebted the Swiss National Science Foundation who financed most of the experimental work described here on the growth kinetics of $E$. coli (projects Nr. 3.625-0.87, 31-30004.90 and 31-30004.90/2) and to C.A. Mason for linguistic help.

\section{References}

Babel W (1982) Energetische und biochemische Aspekte der Mischsubstratfermentation. In: Ringpfeil M(Ed) Abhandlungen der Akademie der Wissenschaften der DDR (N2). 'Biotechnologie' (pp 183-188). Akademie Verlag, Berlin

Bader FB (1982) Kinetics of double-substrate limited growth. In: Bazin MJ (Ed) Microbial Population Dynamics (pp 1-32). CRC Press, Boca Raton

Baidya TKN, Webb FC \& Lilly MD (1967) The utilization of 
mixed sugars in continuous fermentation. I. Biotechnol. Bioeng. 9: 195-204

Baltzis BC \& Fredrickson AG (1988) Limitation of growth rate by two complementary nutrients: some elementary but neglected considerations. Biotechnol. Bioeng. 31: 75-86

Bazin MJ (Ed) (1982) Microbial Population Dynamics. CRC Series in Mathematical Models in Microbiology. CRC Press, Boca Raton

Blanch H \& Yoon H (1977) Competition for mixed substrates by microbial populations. Biotechnol. Bioeng. 19: 1193-1210

Busby SJW (1986) Positive regulation in gene expression. In: Booth IR \& Higgins CF (Eds) Regulation of Gene Expression -25 Years on (pp 51-77). University Press, Cambridge, UK

Button DK (1985) Kinetics of nutrient-limited transport and microbial growth. Microbiol. Rev. 49: 270-297

Button DK (1993) Nutrient-limited microbial growth kinetics: Overview and recent advances. Antonie van Leeuwenhoek (this issue)

Egli T, Käppeli O \& Fiechter A (1982) Mixed substrate growth of methylotrophic yeasts in chemostat culture: influence of the dilution rate on the utilisation of a mixture of glucose and methanol. Arch. Microbiol. 131: 8-13

Egli T, Lindley ND \& Quayle JR (1983) Regulation of enzyme synthesis and variation of residual methanol concentration during carbon-limited growth of Kloeckera sp. 2201 on mixtures of methanol and glucose. J. Gen. Microbiol. 129: 1269 1281

Egli T \& Mason CA (1991) Mixed substrates and mixed cultures. In: Goldberg I \& Rokem JS (Eds) Biology of Methylotrophs (pp 173-201). Butterworth-Heinemann, Boston

Gottschal JC (1993) Growth kinetics and competition - some contemporary comments. Antonie van Leeuwenhoek (this issue)

Harder W \& Dijkhuizen L (1976) Mixed substrate utilization. In: Dean ACR, Ellwood DC, Evans CGT \& Melling J (Eds) Continuous Culture, Vol 6: Applications and New Fields (pp 297314). Ellis Harwood, Chichester

Harder W \& Dijkhuizen L (1982) Strategies of mixed substrate utilization. Philos. Trans. R. Soc. London Ser. B 297: 459-479

Harte MJ \& Webb FC (1967) Utilization of mixed sugars in continuous fermentation. II. Biotechnol. Bioeng. 9: 205-221.

Jannasch HW \& Egli T (1993) Microbial growth kinetics: a historical perspective. Antonie van Leeuwenhoek (this issue)

Kompala ES, Ramakrishna D \& Tsao GT (1984) Cybernetic modeling of microbial growth on multiple substrates. Biotechnol. Bioeng. 26: 1272-1281

Law AT \& Button DK (1977) Multiple-carbon-source-limited growth kinetics of a marine coryneform bacterium. J. Bacteriol. 129: 115-123

Lee AL, Ataai MM \& Shuler ML (1984). Double substrate limited growth of Escherichia coli. Biotechnol. Bioeng. 26: 13891401

Lendenmann U, Snozzi M \& Egli T (1992) Simultaneous utilization of diauxic sugar mixtures by Escherichia coli. 6th International Symposium on Microbial Ecology. Abstracts, p 254. Barcelona, Spain
Lengeler JW (1993) Carbohydrate transport in bacteria under environmental conditions, a black box? Antonie van Leeuwenhoek (this issue)

Magasanik B \& Neidhardt FC (1987) Regulation of carbon and nitrogen utilization. In: Ingraham JL, Brooks Low K, Magasanik B, Schaechter M \& Umbarger HE (Eds) Escherichia coli and Salmonella typhimurium (pp 1328-1325). American Society for Microbiology, Washington, DC

Mankad T \& Bungay HR (1988) Models for microbial growth with more than one limiting nutrient. J. Biotechnol. 7: 161-166

Mateles RI, Chian SK \& Silver R (1967) Continuous culture on mixed substrates. In: Powell PO, Evans CGT, Strange RE \& Tempest DW (Eds) Microbial Physiology and Continuous Culture (pp 232-239). H.S.M.O., London

Matin A (1979) Microbial regulatory mechanisms at low nutrient concentrations as studied in chemostat. In: Shilo M (Ed) Strategies of Microbial Life in Extreme Environments (pp 323339). Dahlem Konferenzen, Berlin

MeGee RD, Drake JF, Fredrickson AG \& Tsuchiya HM (1972) Studies in intermicrobial symbiosis, Saccharomyces cerevisiae and Lactobacillus casei. Can. J. Microbiol. 18: 1733-1742

Monod J (1942) Recherches sur la Croissance des Cultures Bactériennes. Hermann \& Cie., Paris

Münster U (1993) Concentrations and fluxes of organic carbon substrates in the aquatic environment. Antonic van Leeuwenhoek (this issue)

Münster U \& Chróst RJ (1990) Origin, composition, and microbial utilization of dissolved organic matter. In: Overbeck J \& Chróst RJ (Eds) Aquatic Microbial Ecology Biochemical and Molecular Approaches (pp 8-46). Springer, New York

NG FM-W \& Dawes EA (1973) Chemostat studies on the regulation of glucose metabolism in Pseudomonas aeruginosa by citrate. Biochem. J. 132: 129-140

Postma PW (1986) Catabolite repression and related processes. In: Booth IR \& Higgins CF (Eds) Regulation of Gene Expression - 25 Years on (pp 21-49). University Press, Cambridge, UK

Powell EO (1967) The growth rate of micro-organisms as a function of substrate concentration. In: Powell EO, Evans CGT, Strange RE \& Tempest DW (Eds) Microbial Physiology and Continuous Culture. Proceedings of the 3rd International Symposium on Continuous Culture of Microorganisms ( $p p$ 34-55). H.M.S.O., London

Rutgers M, Balk TA \& van Dam K (1990) Quantification of multiple-substrate controlled growth: simultaneous ammonium and glucose limitation in chemostat cultures of Klebsiella pneumoniae. Arch. Microbiol. 153: 478-484

Rutgers M, van Dam K \& Westerhoff HV (1991) Control and thermodynamics of microbial growth. Rational tools for bioengineering. CRC Crit. Rev. Biotechnol. 11: 367-395

Senn H (1989) Kinetik und Regulation des Zuckerabbaus von Escherichia coli ML30 bei tiefen Zuckerkonzentrationen. PhD Thesis ETH Nr. 8831, Zürich

Senn H, Lendenmann U, Snozzi M, Hamer G \& Egli T (1993) The growth of Escherichia coli in glucose-limited chemostat 
cultures: A reexamination of the kinetics. Biochim. Biophys. Acta (submitted)

Silver RS \& Mateles RI (1969) Control of mixed-substrate utilization in continuous cultures of Escherichia coli. J. Bacteriol. 97: 535-543

Simkins S \& Alexander M (1984) Models for mineralization ki- netics with the variables of substrate concentration and population density. Appl. Environ. Microbiol. 47: 1299-1306

Wanner U \& Egli T (1990) Dynamics of microbial growth and cell composition in batch culture. FEMS Microbiol. Rev. 75: 19-44 